\title{
INGMAR BERGMAN E A FILOSOFIA EXISTENCIAL: NOTAS SOBRE O FRACASSO E A MATURIDADE AMOROSA
}

INGMAR BERGMAN AND EXISTENTIAL PHILOSOPHY: NOTES ON FAILURE AND THE MATURITY LOVE

\author{
Rafael Leopoldo*
}

\begin{abstract}
"Minha doce irmã/ Pensa na manhã/ Em que iremos/ numa viagem/ Amar a valer/ Amar e morrer/ No país que é a tua imagem!/ Os sóis orvalhados/ Desses céus nublados/ Para mim guardam o encanto/ Misterioso e cruel/ Desse olhar infiel brilhando através do pranto”
\end{abstract}

Charles Baudelaire

\section{RESUMO}

O presente texto visa analisar a experiência cinematografia de Ingmar Bergman, e principalmente seu filme Monika e o Desejo, como também vários autores da filosofia da existência, para refletir sobre o fracasso e a maturidade amorosa. Com relação à filosofia existencial são salientados os autores Jean-Paul Sartre e Albert Camus. Com relação ao primeiro filósofo aponto, principalmente, a sua visão das relações humanas como conflitivas, a vontade de solidão dos amantes, o ser em abertura para o outro, como também a liberdade. Com relação ao segundo filósofo saliento o seu conceito de "absurdo" e as relações que podem se tornar mecânicas, o mundo que pode desmoronar na perda de sentido. Ao final do texto tento esboçar algumas hipóteses, sobre uma famosa cena deste filme. Trata-se do planoolhar de Monika que foi comentado por Jean-Luc Godard. É exatamente esta cena o cume sobre estas notas do fracasso e também da maturidade amorosa.

PALAVRAS-CHAVES: Filosofia da existência. Fracasso amoroso. Amor. Ingmar Bergman.

\section{ABSTRACT}

This paper aims to analyze the cinematography experience of Ingmar Bergman, especially in his movie Summer with Monika, as well analyze several authors in the philosophy of existence. The point is to ponder about failure and love maturity. With respect to existential philosophy are stressed authors as Jean-Paul Sartre and Albert Camus. About the first philosopher, I pointed mainly his vision of human relation as conflictual, and the will of solitude of some lovers, being in openness to the other, and the question of freedom. About the second philosopher, I emphasize his concept of absurd and relationships that can became

\footnotetext{
${ }^{*}$ Rafael Leopoldo é mestre em psicologia pela Universidade Federal de Juiz de Fora (UFJF). Pós-graduado pela Faculdade Latino-Americana de Ciências Sociais (FLACSO) e graduado em filosofia pela Pontifícia Universidade Católica de Minas Gerais (PUC-MG). E-mail: ralasfer@gmail.com
} 
mechanical, the world can fall apart in total loss of meaning. At the end of the text, I try to outline some hypotheses on a famous scene from this movie. The passage is when Monika looks straight in the camera; Jean-Luc Godard commented this scene. It is exactly this part the top on these notes about the failure and the maturity love.

KEYWORD: Philosophy of Existence; Failed love; Maturity Love; Ingmar Bergman.

\section{INTRODUÇÃO}

O presente artigo está dividido em quatro partes além da introdução e o tópico sobre a psicanálise existencial. A primeira parte é chamada de "ideia fixa na imagem e ideia fixa no conceito". Nesse ponto é salientada a importância do conceito para a filosofia como também para o cinema, com relação à experiência cinematográfica de Ingmar Bergman, cineasta que tem forte vínculo com a filosofia existencial. Isso não só com relação às temáticas, ele é conhecedor de diversos autores existenciais e mais visceralmente do filósofo Albert Camus. É necessário lembrar que Bergman levou a peça Calígula de Camus ao teatro. Em sua biografia chamada Lanterna mágica ele simplesmente diz "ofereceram-me um começo generoso: Calígula de Albert Camus" (Bergman, 1995, p. 164). Outros pontos de conexão interessante são as relações da peça Entre quatro paredes, de Jean-Paul Sartre e o filme Prisão, de Bergman, cujo inferno não está em um além-mundo, mas é a convivência com o outro. Faço então neste primeiro mote uma relação entre uma ideia fixa na imagem (cinema) e uma ideia fixa no conceito (filosofia).

A segunda parte do artigo envolve mais a filosofia de Sartre e o entendimento das relações enquanto conflitos, tendo como referência a obra $O$ ser e o nada, que faze parte de suas obras de psicologia existencial. Nela existem capítulos fecundos, para desenvolver qualquer argumento que se relacione ao contato com a alteridade. Nessa segunda parte são salientadas algumas perspectivas do conflito originário, como relação com o outro, relação de embate por excelência, e Sartre nos dá alguns dos porquês desses conflitos.

$\mathrm{Na}$ terceira parte, “O verão: a solidão dos amantes”, volto-me mais profundamente ao filme, já que é um belo encontro que Bergman nos mostra, um encontro entre os personagens. Sente-se o cheiro de verão no ar, o frescor do amor, as promessas, e, sobretudo as imagens idílicas (o naturalismo bergmaniano). Venho salientar que é um olhar que não se preocupou em relacionar a influência do escritor Strindberg e sua peça Senhorita Julia com relação ao filme Monika e o desejo, relação que poderia ser frutífera para discutir uma possível força desviadora da mulher, um terceiro sexo negativo que nos mostra Strindberg. Deixando de lado 
a aproximação entre as duas heroínas, volto-me para uma vontade de solidão dos amantes, apresentada no filme. É esta vontade de solidão que relaciono com a filosofia de Sartre, esta solidão na verdade também mostra uma fragilidade. Este momento dos dois personagens é belíssimo, eles transbordam em significações um para o outro e tornam-se generosidades.

A última parte é nomeada, "A maturidade do amor em um plano-olhar”, e fiz questão de transformar este plano-olhar em um duplo sentido. $\mathrm{O}$ primeiro se trata da técnica que Bergman usa. O segundo é uma reflexão sobre aquele mesmo olhar, que o cineasta Jean-Luc Godard comenta de uma forma "moralista" de acordo com Bergala (2005), mas não deixa de ser emblemática a citação onde Godard escreve que Monika prefere escolher o inferno em vez do céu. $\mathrm{O}$ momento em que Monika olha para a câmera são os segundos de cumplicidade, e levanto alguns apontamentos com relação a este momento - mas, também é a respeito de quando ela resolve não mais estar com Harry, jovem que até então tinha passado um belo verão. Tem-se a traição, porém poderíamos ser mais sutis e falar da traição de um sentimento, quando se diz amar e então este sentimento simplesmente muda. A maturidade começaria neste ponto, pois é o reconhecimento de uma experiência de fracasso. Relaciona-se aqui a escolha de Monika com um projeto de ser, um desejo de ser.

\section{A PSICANÁLISE EXISTENCIAL: UM DESEJO DE SER}

Daniela Ribeiro Schneider, em seu livro Sartre e a Psicologia Clínica, faz interessantes apontamentos entre Sartre e a psicologia. Penso que dois aspectos estão bem pontuados no texto de Schneider: 1) Sartre e sua convivência com diversos psicanalistas; 2) a psicanálise existencial e empírica na obra de Sartre. Assim, a autora expõe, por exemplo, a relação pessoal de Sartre com Daniel Lagache, J.B Pontalis, Polizer etc. A respeito da obra de Sartre a autora faz todo um percurso nos livros do filósofo, no intuito de enfatizar uma psicologia clínica. Então quando pensamos a respeito de Sartre no conjunto de sua obra e ainda com um olhar para a clínica e a psicanálise, podemos perceber que o autor francês não se limita a ter somente uma leitura crítica destes saberes, mas sim, ele produz, a sua maneira, uma psicanálise existencial.

Schneider, ainda no livro citado, coloca indicativos para uma psicologia clínica em Sartre. Trata-se de compreender que o livro $O$ ser e o nada tem o potencial de transbordar para uma psicologia sartriana. Ela salienta a experiência de Laing e Cooper e a criação de comunidades terapêuticas na década de 1970. Menciona também, Betty Cannon, e o livro 
Sartre e a Psicanálise. Mais próximo do contexto brasileiro tem-se a experiência do NUCA ${ }^{1}$ em Florianópolis, Santa Catarina, que reúne diversos pesquisadores dedicados ao estudo da obra de Sartre, e colocando uma metodologia psicoterapêutica totalmente sustentada na psicologia sartriana. Desta forma, compreendemos que há todo um trabalho que envolve a psicologia em Sartre, porém, neste trabalho não se encontra um estudo clínico, ou ainda, uma tentativa de abordagem estritamente sartriana. Tem-se o uso de alguns conceitos do filósofo que são usados na clínica existencial para a análise de um filme de Bergman.

Mas, mesmo que este texto adentre na análise de um filme seria necessário nos perguntarmos: qual é o método para uma análise existencial? Uma resposta completa a esta pergunta fugiria do escopo de um artigo, mas não podemos deixar de tocar, mesmo que superficialmente, no tema. Comecemos por deixar claro que o existencialista não teve uma experiência clínica. Os estudos do autor foram de ordem teórica, e a sua prática se deu por meio de empreendimentos biográficos, ou seja, ele usou a vida de determinadas pessoas criando biografias e usou o seu arcabouço teórico para exemplificar o seu método. Schneider cita repetidas vezes que a psicanálise existencial ainda não teria encontrado o seu Freud e é por isso que para a autora é tão importante fazer uma delimitação do que é uma psicanálise existencial na obra de Sartre, porque fundamenta uma prática, mesmo que ela não tenha sido usada pelo o autor no cenário clássico: o setting psicanalítico com o seu divã. Além do empreendimento biográfico de Sartre, temos um capítulo do livro $O$ ser e o nada que é de vital importância para a clínica, trata-se do capítulo 2, onde a primeira parte é nomeada de "psicanálise existencial". É debruçado sobre esta parte que podemos remontar a nossa pergunta inicial.

Sartre, ao escrever no capítulo sobre a psicanálise existencial coloca o princípio, o objetivo, o ponto de partida e o método desta psicologia. O princípio se encontraria na assertiva de que o homem é uma totalidade. O indivíduo se expressaria por inteiro em cada um dos seus atos, em cada palavra, em cada olhar, assim não haveria um só gesto que não fosse revelador desta totalidade. O objetivo da psicanálise seria decifrar os comportamentos empíricos do homem, clarificá-los ao máximo. O ponto de partida seria a experiência e tendo como ponto de apoio a compreensão pré-ontológica que o homem tem da pessoa. O método é o comparativo, porque cada comportamento do indivíduo simboliza a sua escolha fundamental, o seu desejo de ser, ao mesmo tempo, a escolha pode disfarçar este projeto de ser, e por meio da comparação entre condutas é que brotaria a possibilidade de revelar a experiência única do sujeito. O existencialista escreve sobre a finalidade da investigação que

\footnotetext{
${ }^{1}$ Núcleo Castor - estudos e atividades em existencialismo - site: www.nuca.org.br
} 
“deve ser a descoberta de uma escolha, e não de um estado, esta investigação deverá manter sempre em vista que seu objeto não é um dado soterrado nas trevas do inconsciente, mas sim uma determinação livre e consciente" (SARTRE, 1997, p. 701). Estes são alguns elementos da psicanálise existencial sartriana em relação ao método, conceitualmente, penso ser necessário adentrarmos ao menos em um aspecto deste empreendimento. A ideia de projeto de fato seria interessante para uma introdução, porém analiso este conceito sobre o viés do desejo, porque o existencialista tem uma concepção importante do desejo e que ainda se diferencia do compreendido tal como a psicanálise freudiana e os seus principais ramos o entendem.

A escolha envolve a construção de um projeto e "o projeto é concretizado pelo desejo de ser. Todo homem realiza seu projeto fundamental através de seu desejo de ser. É esse desejo de ser que o move, que o lança em direção ao mundo" (SCHNEIDER, 2011, p. 128). A psicanálise freudiana já havia dado um lugar importante a noção de desejo em sua abordagem do sujeito, porém o existencialista apresenta dois erros da perspectiva de um psicólogo empírico. $\mathrm{O}$ primeiro erro seria a ilusão de que o desejo seria uma substância, assim compreender que o desejo existe no homem como um conteúdo da sua consciência. Contudo, Sartre adota outra perspectiva, pois para o autor o desejo não é um a priori da realidade humana, o desejo é formado em cada escolha do indivíduo. O desejo de ser se manifesta nas escolhas, nas ações concretas dos indivíduos. O segundo erro seria considerar terminada a investigação, quando alcançado, por exemplo, um "catálogo" dos desejos de determinado indivíduo. Como já posto, Sartre compreende em sua psicanálise existencial o ser humano como uma totalidade, desta forma, o que se exigiria é uma livre unificação, ou seja, o seu projeto original.

\section{IDEIA FIXA NA IMAGEM E IDEIA FIXA NO CONCEITO}

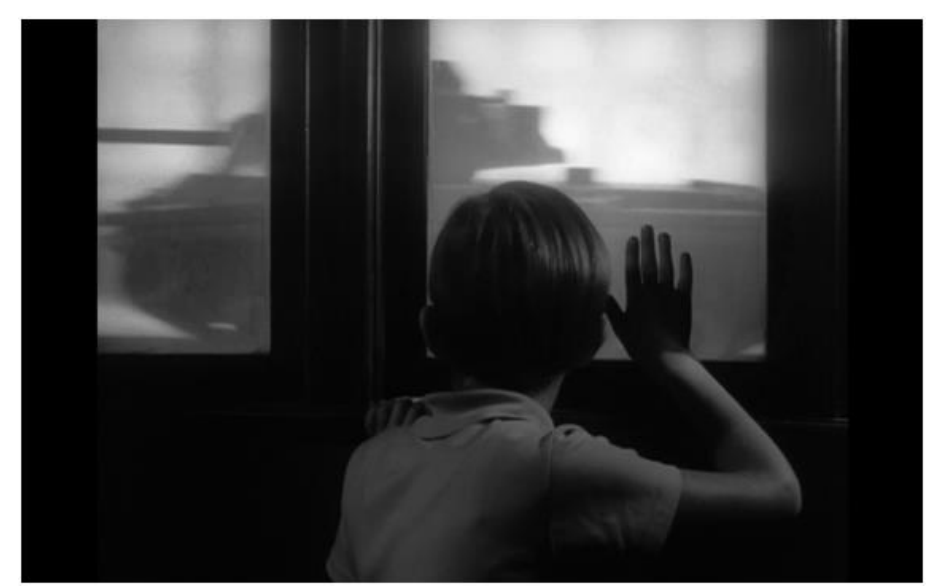

Figura I: Cena do filme $O$ silêncio, no qual a ideia fixa na imagem faz referência às neuroses de uma guerra. Estar em desconforto contínuo e espreitado por algo, que não se sabe bem o que de fato é. Tais sentimentos que se trata da guerra passa para a relação dos personagens, assim tendo um conceito fixo durante o filme. 
Uma ideia fixa em uma imagem em movimento, assim parecem ser os filmes do cineasta sueco Bergman, como a arte do pensar da filosofia existencial parece ser uma ideia fixa dentro do conceito. A imagem passa de tal forma a dar uma ilusão de movimento, enquanto há um pensamento fixo que passa a se repetir. Este pensamento, com respeito a Bergman, de forma mais genérica, trata-se das relações humanas nos seus mais diversos ângulos. Com relação ao existencialismo e a filosofia da existência, um dos grandes temas é a existência e sua possibilidade de significação, possibilidade de criação.

Bergman, como também a filosofia da existência, trabalha com questões interessantes, como o conceito e a estética. Para a filosofia o conceito é vital, e de forma bem ampla o conceito é o processo que torna possível a descrição, a classificação e a previsão dos objetos cognoscíveis, também é uma atividade criativa. Entretanto o conceito não é apenas um nome, visto que um mesmo conceito pode ser expresso por vários nomes, o conceito então passa a se relacionar a várias técnicas simbólicas. Na cinematografia de Bergman o conceito se dá via filme literário. Este cinema literário, por sua vez, não é uma mera adaptação de um romance ou uma novela. Também esta forma de criação não é somente ou necessariamente aquela que valoriza em demasia o diálogo, mas é uma que conta com o conceito, e o conceito é posto em imagem.

O filme $O$ silêncio, que pertence a "Trilogia do Silêncio", também conhecida como a “Trilogia da Fé", juntamente com os filmes Através de um espelho e luz de inverno, nos mostra um exemplo do que é o conceito dentro do projeto cinematográfico de Bergman. $\mathrm{O}$ filme inicia em um compartimento de um trem, no qual um garoto olha pela janela uma interminável linha de tanques de guerra. Poderíamos entender que ali estaria acontecendo uma guerra, entretanto no momento em que o garoto e as duas irmãs, Esther e Anna, saem do vagão, vê-se que não há nada com relação a uma guerra, a guerra não está acontecendo realmente. A imagem ali estava para criar uma impressão de neurose que perpassa o filme. Outro exemplo desta técnica se encontra em contornos dramáticos fortíssimos no filme Noites de circo. Em uma cena deste filme o "palhaço" do circo é avisado por um amigo que sua mulher está tomando banho com diversos militares. A mulher do palhaço é exibida no filme a todo o momento como alegre e sensual, mas em um momento específico a imagem desta mulher é intercalada por imagens de militares e de diversos canhões sendo disparados. Os canhões são claramente um simbolismo para o ato sexual. Bergman mostra canhões fálicos em pleno orgasmo, a potência militar contra a fragilidade do bufão. Tem-se com esta cena ao mesmo tempo o efeito de conflito e o desespero do palhaço. 
Existem diferenças claras entre um discurso fílmico e o filosófico, entretanto é válido salientar que ambos abordam uma arte de pensar e expor um pensamento. Vários filósofos existencialistas foram além do nicho filosófico para adentrar o âmbito literário. Trabalhar nestas duas áreas não é somente uma tentativa de popularizar a filosofia por meio da literatura, o esforço é mais significativo - existe uma diferença do discurso filosófico com relação ao literário. Simone de Beauvoir não conseguia decidir entre a beleza da literatura e o enlevo da filosofia, no primeiro ela poderia expressar a singularidade e no segundo o vigor do pensamento conceitual, a abstração. As duas formas são únicas, e cada qual tem a sua linguagem, o que não nos impede de caminhar pela literatura, pela filosofia como também pelo discurso do cinema. Este texto tem este intuito, de caminhar por uma filosofia existencial e a cinematográfica de Bergman.

\section{O CONFLITO COMO RELAÇÃO ORIGINÁRIA}

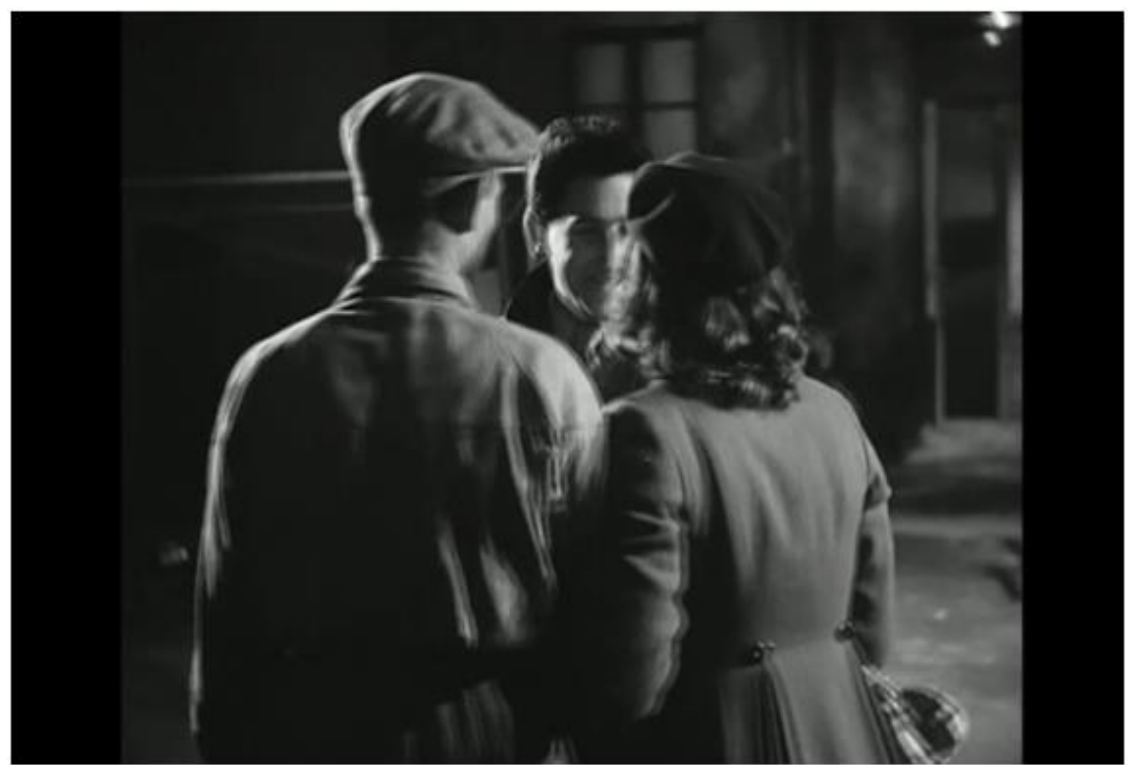

Figura II: Imagem de uma das cenas iniciais do filme Monika e o desejo em que se tem Harry e Monika caminhando juntos de mãos dadas, e na frente do casal aparece Lelle.

No filme Monika e o desejo, as primeiras cenas se passam dentro de uma cidade grande. As falas então se tornam ruidosas, o som do trânsito é intenso, os bêbados perpassam a noite com seus zumbidos. Os planos são fechados, claustrofóbicos como as cidades. É neste clima que Bergman nos mostra uma relação de mocidade. O jovem Harry vive com o pai doente e uma tia, e ele tem um emprego que não gosta. É um garoto esforçado, um jovem que logo se tornaria um adulto. Sua namorada Monika trabalha na quitanda. Ela tem uma 
sensualidade natural e por vezes demais ingênua. Ela parece que foi de todos daquele trabalho, mas ao mesmo tempo não é de ninguém, Monika repudia o toque forçoso dos homens a sua volta. Os gestos dela são tão naturais que parecem impensados. É sensível e chora ao ver um filme com Harry, ao mesmo tempo brinca como criança ao imitar a cena romântica do filme que viu junto com o namorado. Ela parece uma criança no corpo de uma adulta, e às vezes uma adulta no corpo de uma criança, e esta é a fórmula na qual toda moral se esvai. O desejo e a beleza das crianças são enormes, o que às vezes lhes falta é o poder, e se este está nas mãos da pequena criança há então uma mulher fatal, mas este olhar tem o seu próprio tempo de construção.

A Figura II mostra exatamente estes dois personagens, Harry e Monika, mas também um antigo relacionamento de Monika, um rapaz que se chama Lelle. Sobre a relação destes três convém ressaltar alguns pontos da filosofia de Jean-Paul Sartre e seu livro chamado $O$ ser e o nada. Livro que deu grande visibilidade para o existencialismo francês. Nesta obra há um capítulo somente dedicado ás relações com o Outro, relação que é originariamente de conflito. Aqui vamos salientar a questão do ente para-si que é uma totalização em curso, ela não se exaure, a questão do Olhar que torna o outro objeto, e também abordar o ser-Para-outro que nos mostra implicações no projeto amoroso, e alguns outros pontos que envolvem estes conceitos.

Sartre nos diz que o indivíduo é um ente para-si, é consciência, mas consciência não substancial como, por exemplo, a res cogita cartesiana, trata-se de ser pura relação com alguma coisa. $\mathrm{O}$ indivíduo é um projeto que procura uma totalização, "não existe sujeito sem projeto. Mesmo não ter um projeto é ainda um projeto; quer dizer, o homem, ao lançar-se no mundo, persegue um fim, mesmo que não tenha clareza qual é” (SCHNEIDER, 2011, p. 128). O projeto diz respeito a um desejo de ser, um desejo distinto do freudiano já que não remonta necessariamente a sexualidade, mas sim há um desejo constituído na prática do sujeito, no seu cotidiano. Contudo, o homem nunca se totaliza, nunca se transforma totalmente em uma coisa, em um ente em-si, um ser maciço que não teria um fora ou um dentro, um ser que simplesmente é. O homem é uma eterna totalização em curso, um vir-a-ser, e vai se criando com a sua liberdade mediante as escolhas e a relação com os outros. Não há o ente para-si sozinho, pois o indivíduo se encontra entre outras consciências, e é também um ser-Paraoutro. Esta relação entre as consciências é o que Sartre nos diz ser marcada pela relação entre liberdades. Na visão dele: 
Enquanto tento livrar-me do domínio do outro, o outro tenta livrar-se do meu; enquanto procuro subjugar o outro, o outro tenta me subjugar. Não se trata aqui, de modo algum, de relações unilaterais com um objeto-Em-Si, mas sim de relações recíprocas e moventes. (...) O conflito é o sentido originário do ser-Para-outro. (SARTRE, 1997, p. 454).

Sartre exemplifica esta relação de reconhecimento com a questão do olhar, pois a revelação do outro se dá inicialmente por este visar. Com o olhar se experimenta o ser-Paraoutro como posse e como possuído. Diante desta posse se detém um segredo. O segredo do que o outro é. $\mathrm{O}$ outro tem a consciência de me possuir e eu, como consequência, tenho a experiência da minha objetividade. Contudo, tento recuperar o meu ser, assimilando o outro, reconhecendo-o como liberdade, pois não poderia recuperar o meu ser, se o visse como um ser petrificado. Neste ponto há um problema, já que para recuperar o meu ser deveria conhecer a subjetividade alheia, adentrar naquele pensamento, e tal projeto é, por princípio, irrealizável. Haveria que acabar com a alteridade para concluí-lo. O projeto que é ser o outro para si mesmo não logra. O que temos é o conflito para tentarmos obter o nosso ser, que está fundamentado de forma exterior.

A relação com os outros é então dantesca. $\mathrm{O}$ outro se torna um mal necessário, um empecilho, embaraço, entreve, barreira, estorvo e também um inferno. Uma liberdade é ameaçada por outra. É impossível obrigar o outro a pensar o que eu quero, assim me definindo por conta própria. O pensar do outro me escapa. O olhar do outro me censura, acolhe, admira, como também me torna objeto de reprovação. Tornamo-nos frágeis ao olhar do outro, o nosso ser que é possibilidade, que está em curso, pelo o olhar do outro é definido, é projeto concluído. $\mathrm{O}$ que seria liberdade se transforma em algo fixo. O outro suprime os possíveis, assim petrifica o ser: o torna pedra, um eu-objeto.

Agora, se voltarmos para a segunda figura apresentada neste texto veremos três pessoas, mas cada qual com sua subjetividade centrada e petrificando o outro, nas próprias relações. Harry caminha de mãos dadas com Monika, os dois então estariam em um mundo estável no qual o amor um pelo o outro é o fundamento das suas próprias ações. Contudo, Harry e Monika naquele caminho encontram Lelle, e este petrifica o casal, e faz especialmente Harry lembrar que aquele amor que ele tem, é um amor entre outros amores. Sartre nos fala que este é o amor no mundo:

Pelas contingências dos encontros; torna-se amor no mundo, objeto que pressupõe o mundo e pode, por sua vez, existir para outros. O que o amante exige é por ele traduzido com palavras desajeitadas contaminadas de "modos de coisas" ("choisismes"); diz ele: "fomos feitos um para o outro", ou usa a expressão "almas 
gêmeas". Mas é preciso interpretar assim: o amante bem que sabe que o "serem feitos um para o outro" refere-se a uma escolha originária. Essa escolha pode ser a de Deus, enquanto ser que é escolha absoluta; mas Deus só representa aqui a passagem ao extremo limite dessa exigência do absoluto. Na verdade o que o amante exige é que o amado dele faça a escolha absoluta. Significa que o ser-no-mundo do amado deve ser um ser-amante. (SARTRE, 1997, p. 462).

O desejo é que o outro seja uma escolha absoluta, e para isso recorre ao fatalismo das frases tão comuns que Sartre nos mostra como, por exemplo, "somos feitos um para o outro" ou ainda a ideia tão admirável de uma "alma gêmea". Porém, também somos um ser-Paraoutro, um terceiro nos olha e nos faz lembrar que não somos um eixo de referência absoluto. Este terceiro, exemplificado, é o personagem de Lelle, que não somente leva esta recordação como também olha para Monika transformando-a em um objeto amoroso de Lelle. É contra estes pontos que surgem diante do outro o eterno desejo de solidão dos amantes, ou ainda uma constante insegurança. Esta solidão vai ser um belo verão entre Harry e Monika, em uma realidade quase idílica, pois nem só das flores de lótus (2006) vivem os habitantes do nosso arquipélago amoroso.

\section{O VERÃO: A SOLIDÃO DOS AMANTES}

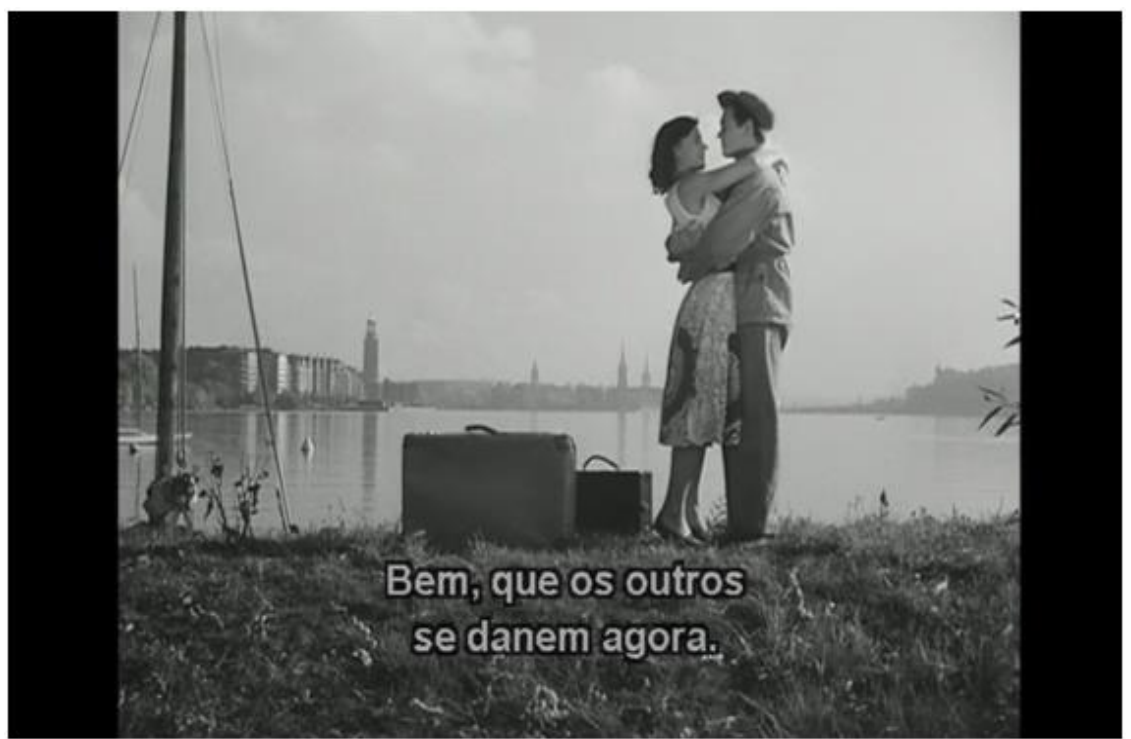

Figura III. Esta cena é uma parte do filme no qual Harry e Monika resolvem viajar juntos, deixando para trás todos os outros, que lhes pareciam um empecilho à felicidade.

Harry simplesmente vive indo continuamente ao seu trabalho, do qual não gosta. Os pensamentos dele são para Monika, e é isso o que lhe espairece. Ainda Harry tem uma estranha relação com o pai. Monika por sua vez tem uma vida ainda mais difícil. Trabalha na quitanda, onde tem vários ex-namorados que nem sempre a respeitam. As crianças a chamam 
na rua de "Monika suja". Em sua casa encontra o seu pai na maioria das vezes embriagado. Esta estrutura de família é algo raro nos filmes dirigidos por Bergman, que geralmente trata de uma família burguesa ${ }^{2}$ e ainda de um ambiente burguês. Monika e Harry têm necessidades econômicas, não somente por serem jovens, mas devido à estrutura das famílias - Monika é pobre e Harry um pequeno burguês com o seu pai adoentado. A gota d'água para Monika é quando o pai dela chega bêbado comemorando os 25 anos de casamento, então o pai bate na filha, assim Monika sai de casa e vai encontrar com Harry, que estava no hospital cuidando de seu pai. Harry não pode ficar com Monika na casa dele devido a uma tia, então Harry a leva para o barco de seu pai, e é lá que os dois jovens passam a morar. Cada um deles tinha relações conflituosas com outros, mas naquele barco há uma boa solidão. E se pensarmos em Freud e também Otto Rank é possível ver aquele barco e a água como a calmaria do útero, como um regresso a um lugar ideal, onde não havia diferença entre o interno e o externo, não havia ainda chegado o trauma do nascimento. É neste momento que Harry e Monika falam de terceiros: "que os outros se danem agora", "gostaria de matar todos que querem nos impedir e nos fazer rastejar". Desta forma, eles se preparam para um verão juntos, para um espaço pessoal. Eles então irão para longe da cidade e mais perto da natureza, para um local mais longínquo dos outros e mais perto deles mesmos.

No local onde Harry e Monika estão, há também uma mesa com três velhos bebendo, um deles, ao ver os dois diz "Há um toque de verão no ar", aquele velho reconhece o amor se iniciando. Este verão chega colocando risos e esperança na face de Harry e Monika. Nas cenas é valorizada a natureza, a passagem do tempo, a transposição se dá de um lago para uma chuva, da chuva para um céu no qual o sol começa a se mostrar, o arco-íris e depois o soprar do vento. A natureza externa e interna vai mudando naquele espaço pessoal. Juntos em frente a uma fogueira eles falam sobre suas vivências e expectativas:

Harry: Sabe... Eu sempre fui sozinho, de certo modo. Minha mãe ficou doente quando eu tinha 5. E morreu quando eu tinha 8. Isso afetou meu pai de maneira estranha: ele ficou muito quieto. Todas as noites, comíamos em casa, eu e ele, sem falar uma palavra. Só ficávamos sentados.

Monika: Nunca fiquei sozinha em casa. Os meninos são barulhentos e quebram tudo. Papai chega em casa bêbado, gritando e, às vezes, bate na gente. Mas ele é engraçado também.

\footnotetext{
${ }^{2}$ Claro que seria possível apontarmos que Monika e Harry são mais burgueses que os burgueses, posto que ambos procuram fazer parte desta composição social e é somente por meio dela que lhes parecem viável a existência. Talvez, a única tentativa para criar um novo horizonte existencial esteja no momento edílico que ambos vivem juntos e afastados da sociedade, porém este momento é desfeito rapidamente.
} 
Harry: Sua vida não foi melhor do que a minha. Monika, pensei em estudar em casa. Se eu me dedicar, posso me tornar um engenheiro, sempre gostei de máquinas. No ano passado, consertei o motor do barco, papai não conseguiu.

Monika: Poderíamos nos casar quando você se tornar um engenheiro, não seria legal? Eu acho que estou grávida.

Harry: É verdade? Então vamos voltar, preciso trabalhar, e você precisará se alimentar direito.

Monika: Eu não voltarei, quero passar esse verão exatamente desse jeito. Harry, você é a melhor pessoa que eu conheço.

Harry: Monika... Você e eu faremos algo na vida. Só vamos gostar um do outro. Vou estudar e trabalhar para que possamos nos casar e viver numa casa boa e ter coisas boas, nós e o bebê.

Monika: E quando você chegar em casa, o jantar vai estar pronto e nós passearemos com as crianças aos domingos e eu não precisarei trabalhar, e ficarei em casa e terei sempre boas roupas.

Harry: teremos tudo juntos, vamos ficar juntos.

Monika: Só você e eu.

Este diálogo é belo, porque quem sabe o amor também seja isso: uma ilusão de eternidade. Ambos planejam uma vida juntos, mas também estão lúcidos com relação ao futuro de uma forma quase intuitiva, pois Harry lembra que ele deve voltar para o trabalho, e Monika diz que ela quer aproveitar aquele verão como ele - desta forma ela mostra seu amor por ele e faz aquele instante se prolongar. Neste momento há esta eterna vontade de solidão dos amantes. Uma grande parte deste verão não se tem o outro. O mundo é Harry e Monika. Não haveria o terceiro que torna o amor deles apenas um objeto. Ou um terceiro que faça com que Harry ou Monika acordem. Mas o que seria este estado de sonho antes do despertar em que os amantes estão envolvidos? Este estado é o de colocar o seu próprio ser na liberdade do outro, para assim se manter a salvo. É fazer-se objeto-fascinante, tornar-se sedução; fazer-se fundamento do outro, e dentro deste fundamento existir a liberdade do outro. Sartre nos diz o seguinte:

\footnotetext{
Sou porque me prodigalizo. Essas amadas veias em minhas mãos existem beneficamente. Que bom é ter olhos, cabelos, sobrancelhas, e esbanjá-los incansavelmente em um transbordamento de generosidade a esse desejo infatigável que o outro faz-se livremente ser. Em vez de sentirmo-nos "supérfluos", agora sentimos que esta existência é recuperada e querida em seus menores detalhes por uma liberdade absoluta, a qual nossa existência ao mesmo tempo condiciona e nós mesmos queremos com nossa própria liberdade. Este, o fundo da alegria do amor, quando existe: sentimos que nossa existência é justificada. (SARTRE, 1997, p. 463).
}

Contudo, a qualquer momento, pode acontecer o despertar, e neste momento Harry poderia ver Monika como tantas outras mulheres, ela já não seria o fundamento. É isto que a solidão dos amantes evita, este possível despertar, porque aquele indivíduo que então fascinava, pode deixar de fascinar, aquele indivíduo que leva tanto frescor ao coração, pode 
nos trazer agora o sentimento de indiferença, aquele ser tão belo que dava sentido e justificativa toda uma vida, pode se tornar um ser entre tantos outros seres, um indivíduo qualquer, e não mais aquele amor que se autodetermina passional. Esta bolha de sabão é frágil demais, e pode perder o seu brilho a qualquer momento.

Em outro ponto do texto escrevia que fora um verão "quase" edílico, este quase é importante, porque naquele verão também surge Lelle com quem Harry briga de forma violenta. Também surge o desejo de Monika de se alimentar com coisas diferentes, de nutrirse com o diferente, então ela vai a uma casa para assaltar comida - e também há a gravidez de Monika. Diante de tantos entreves e ao fim daquele verão, eles então voltam para a cidade. Agora, trata-se de saber se aquele amor de puberdade sobreviverá ou não, já que não se vive sempre em verões.

\section{A MATURIDADE DO AMOR EM UM PLANO-OLHAR}

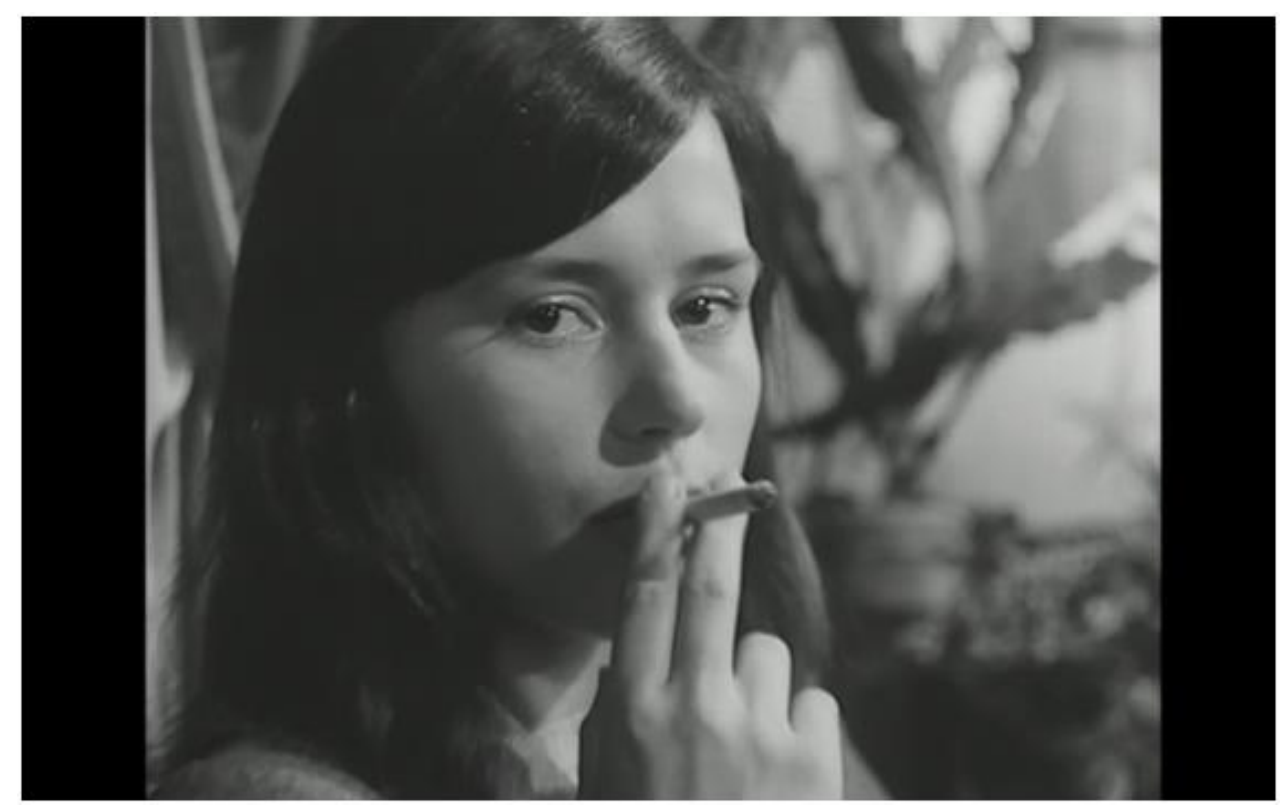

Figura IV. Uma regra da fotografia que passou para o cinema foi jamais olhar para a câmera. Tal regra se baseava no medo de que a fotografia pudesse tirar a alma daquele que é fotografado, ou filmado. Bergman faz um belo Plano-olhar, no qual Monika olha os nossos olhos fixamente.

Uma ilha na qual há um lampejo de um relacionamento, do qual poderia ser uma conexão real entre duas pessoas. Ou uma ilha da qual se busque somente um tempo de prazer, companhia, carinho. Harry e Monika não estão mais dentro daquele verão, mas em um caminho de volta para a cidade, no qual há a atmosfera cinza que já conhecemos, e mais um agravante que é a gravidez de Monika. Ambos passam então a enfrentar o cotidiano que tantas 
vezes vem abaixo, desmorona na sua perda de significação, mas que também é o mais concreto da vida. Com Camus que temos uma descrição importante deste momento em que o cotidiano ganha contornos de estranheza. O cotidiano, a vida que se torna maquinal simplesmente alguma hora perde o sentido. Não somente o ato maquinal, mas também o outro pode desagregar desumanidade. Camus escreve que:

\begin{abstract}
Em certas horas de lucidez, o aspecto mecânico de seus gestos, sua pantomima desprovida de sentido torna estúpido tudo o que os rodeia. Um homem fala ao telefone atrás de uma divisória de vidro; não se ouve o que diz, mas vemos sua mimica sem sentido: perguntamo-nos porque ele vive. Esse mal-estar diante da desumanidade do próprio homem, essa incalculável queda diante da imagem daquilo que somos, essa "náusea", como diz um autor dos nossos dias, é também o absurdo. (CAMUS, 2005, p. 29).
\end{abstract}

Também não nos é estranho que este mesmo sentimento que toca o nosso peito, aparece não somente com aquele que está distante, como no exemplo do Camus de um homem ao telefone separado de nós por uma divisória de vidro, mas também acontece com aqueles que são mais próximos. Um conhecido torna-se desconhecido. Esta força negativa que saliento no cotidiano é que o casal vai experimentar - e não sobreviverá a esta experiência. O cotidiano corroerá até os ossos da relação.

Harry e Monika se casam e têm uma filha, chamada June Monika. Harry passa cada vez mais a trabalhar e viajar por causa do trabalho, passa as noites em claro cuidando da filha, da qual Monika tem um desdém enorme; ele também passa as madrugadas em claro estudando para um dia ser um engenheiro. Harry está envolto a todo ascetismo da classe média. Monika, por sua vez, está cada vez mais infeliz, não sente afeto pela filha, cria artimanhas para ver a si mesma longe dela, reclama do dinheiro que não tem para o novo vestido, para ver o cinema, como nos primeiros dias que eles se conheceram. Vive com o pouco dinheiro que Harry com ela partilha. Ela não se sente mais bela, acha que o corpo mudou. Harry então sai para mais umas de suas viagens a trabalho, e quando ele sai é que temos a cena em que Jean-Luc Godard escreve que "é o plano mais triste da história do cinema", este plano tão triste diz respeito a um plano-olhar, ao olhar intenso de Monika.

A análise de Godard sobre aquele olhar de Monika é interessante, porque este diretor nos escreve o seguinte:

Deve-se ver Monika e o Desejo, nem se for apenas pelo extraordinário momento quando Harriet Andersson, antes de fazer amor com o homem que já dispensara antes, olha fixamente para a câmera, com olhos de escárnio e dúvida, e nos pede 
para testemunhar sua repulsa por escolher o inferno em vez do céu. É o plano mais triste da história do cinema. (GODARD).

A experiência de um fracasso amoroso é a própria maturação. Interessante notar que a palavra experiência tem na sua etimologia relação com a palavra perigo. A experiência leva em si também esta dimensão, de estar no perigo e também ultrapassá-lo, e assim sendo também reconhecê-lo. Monika escolhe sair com outros homens, prefere trair a estar com Harry. Ou ainda poderíamos dizer que Monika escolhe a sua liberdade em detrimento de qualquer coisa, ela escolhe a transgressão. Ao encontrar com outro, Monika olha fixamente para a câmera, ela nos olha, mas não é somente para testemunharmos a sua repulsa por escolher o "inferno" como diz Godard moralizando aquele olhar. Penso que ela faz algo muito mais ambíguo, ela também nos objetifica com aquele olhar, da mesma forma com que então olhava Harry - por alguns momentos somos Harry Lund. Monika de fato fez uma escolha, e agora ela já não é mais uma criança, ela tem uma filha e suas ações têm peso e significação. Monika parece escolher outros verões, fazer-se arquipélago, largar a filha e multiplicar-se, ser Monika sem Harry e apaixonar-se por Lelles. Talvez, possamos dizer que Monika expressa naquele olhar todo o seu desejo de ser, no menor gesto a escolha original, e nesta escolha podemos ver o futuro que Monika quer realizar.

Monika seria uma Penélope que então para de tecer à espera de Ulisses. Uma Penélope que nega o absoluto. Mas, convém salientar que diferentemente do que pensa Alfeu Trancoso (2010) no seu saboroso artigo sobre a fidelidade, penso que não é a Penélope o ápice da fidelidade, já que não é ela a primeira a reconhecer Ulisses quando ele volta para casa. Quem é verdadeiramente fiel ao herói da Odisseia é o seu velho cão Argos que no mesmo instante que o vê o reconhece. A fidelidade estava muito mais crua com Argos, o abanar de seu rabo e o movimento de suas orelhas do que com o tecer cansativo de Penélope. Todavia, este tecer a respeito da personagem de Bergman cessa.

O filme nos apresenta uma desconcertante igualdade entre o masculino e o feminino, porque se houve uma luta das mulheres em fazer com que o pai reconheça a paternidade do filho, e isso desde a Declaração dos direitos da mulher e da cidadã por Olympe de Gouges, Monika nega a filha. Fato que nos choca mais que a traição, mas este espanto não se daria tão facilmente se fosse mostrado um homem abandonando um filho, porque isto está em um âmbito do ordinário. Monika não nos mostra o que se espera de uma mulher: o extremo amor ao filho (a figura da mãe) e a devoção ao marido (o casamento monogâmico). Talvez então Monika seja uma "mulher fatal", por ser também masculina, por preferir a sua liberdade 
mesmo diante da transgressão. Ela parece não querer perpetuar as escolhas familiares, as escolhas que ela então via a cada dia no seu lar, mas mesmo assim, diante desta situação, diante da concretude da vida Monika escolhe.

Com relação a Harry, também já não haveria o menino-jovem, mas sim um homem. Que mesmo sendo traído a abraça, mas também sente repulsa: parece não existir unicidade de sentimentos. Eles se confessam e cada um vai seguir adiante. Mesmo Harry sendo aquele que diz "ainda tudo pode dar certo". O desejo metafísico de reconciliação, ou a vontade refinada de atar nós, a vontade de haver um encontro. Monika deixa a filha, e Harry passa a cuidar dela. Nas últimas cenas vemos Harry olhando para um espelho d'água. Harry olha para a filha refletida naquele espelho, depois olha para si mesmo, posteriormente o espelho se faz lembrança e ele se vê junto a Monika naquela ilha, por último ele vira e vai embora. Estava no mesmo local onde conheceu Monika. Harry vende suas coisas e é interessante notar que os homens que compram a mobilha da casa de Harry e Monika foram os mesmo que, vendo os dois juntos disseram "há um toque de verão no ar", aqueles velhos sabiam que o amor também acaba. Sabiam literalmente em suas faces marcadas pelo tempo que o amor também acaba. Sabiam que o verão se desfaz, e então compraram os cacos daquele amor, de forma barata, compraram um resto agridoce de juventude.

\section{REFERÊNCIAS}

ADORNO, Theodor; Horkheimer, Max. Dialética do Esclarecimento. Rio de Janeiro: Jorge Zahar, 2006.

BAUDELAIRE, Charles. As Flores do Mal. Tradução: Ivan Junqueira. Rio de Janeiro: Nova fronteira, 1985.

BEAUVOIR, Simone. El existencialismo y la Sabiduría de los Pueblos. Tradução: Horacio Oscar. Argentina: Edhasa, 2009.

BERGALA, Alain. Monika de Ingmar Bergman. Du rapport créateur-créature au cinema. Paris: Yellow, 2005.

BERGMAN, I. Linterna Magica. Espanha: Fabula Tusquets, 1995.

BERGMAN, I. Monika e o Desejo. Suécia: SvenskFilmindustrit, 1953.

BERGMAN, I. Noites de Circo. Suécia: SvenskFilmindustrit, 1953.

BERGMAN, I. O Silêncio. Suécia: SvenskFilmindustrit, 1963. 
BORNHEIM, Gerd. Introdução ao Filosofar. O Pensamento Filosófico em Bases Existenciais. Editora Globo, 1976.

CAMUS, Albert. O Homem Revoltado. Tradução: Valerie Rumjanek.São Paulo: Record, 1999.

CAMUS, Albert. O Mito de Sísifo. Tradução: Ari Roitman e Paulina Watch. São Paulo: Record, 2005.

GODARD, Jean-Luc. Bergmanorama. Cahiers Du Cinéma. n. 85. Jul. 1958.

HOMERO. Odisseia. Trad. Frederico Lourenço. Lisboa: Livros Cotovia, 2003.

LEOPOLDO, Rafael. A Náusea e a Revolta: Comendo Morangos Silvestres com Ingmar Bergman. Existência e Arte. São João Del-Rei. n. 6. 2011.

LYOTARD, Jean-Françoi. (1988). O Pós-moderno. Rio de Janeiro: J.O, 1988.

RANK. Otto. The Trauma of Birth. Now York: Robert Brunner, 1952.

SARTRE, J.P. A Nausea. Rio de Janeiro: Nova Fronteira, 2000.

SARTRE, J.P. O Ser e o Nada. Tradução: Paulo Perdigão. Rio de Janeiro: Vozes, 1997.

SCHNEIDER, Daniela Ribeiro. Sartre e a Psicologia Clínica. Florianópolis: UFSC, 2011.

TRANCOSO, Alfeu. Fidelidade. Sapere Aude. Belo Horizonte. v.1. n.11.1 a sem. 2010. 